\section{Vol. 39, Issue 6, December 2012}

\section{Focus: Current Trends in Tissue Banking (in Cooperation with the DGTI Section 'Tissue Preparations') \\ Coordination: Pruss, A.; Kalus, U. (Berlin)}

Editorial

373 Current Trends in Tissue Banking Pruss, A.; Kalus, U. (Berlin)

Original Articles

376 Virus NAT for HIV, HBV, and HCV in Post-Mortal Blood Specimens over $48 \mathrm{~h}$ after Death of Infected Patients - First Results

Meyer, T.; Polywka, S.; Wulff, B.; Edler, C.; Schröder, A.S (Hanburg); Wilkemeyer, I.; Kalus, U.; Pruß, A. (Berlin)

381 Validation of Virus NAT for HIV, HCV, HBV and HAV Using Post-Mortal Blood Samples

Gubbe, K (Plauen); Scharnagl, Y; Grosch, S; Tonn, T; Schmidt, M Hourfar, M; Karl, A; Seifried, E (Frankfurt/M.); Wilkemeyer, I; Kalus, U (Berlin)

387 Validation of the Microbiological Testing of Tissue Preparations Using the BACTEC ${ }^{\text {TM }}$ Blood Culture System

Schroeter, J.; Wilkemeyer, I.; Schiller, R.; Pruss, A. (Berlin)

391 Comparison of in situ Corneoscleral Disc Excision versus Whole Globe Enucleation in Cornea Donors Regarding Microbial Contamination in Organ Culture Medium - a Prospective Monocentric Study over 9 Years

Schroeter, J; Wilkemeyer, I; Herrlinger, F; Pruss, A (Berlin)

395 CT Lesion Model-Based Structural Allografts: Custom Fabrication and Clinical Experience Brune, J.C.; Hesselbarth, U. (Berlin); Seifert, P.; Nowack, D. (Hamburg); von Versen, R. (Wandlitz); Smith, M.D. (Berlin); Seifert, D. (Apolda)

405 Regional Experiences of Tissue Donation and Forensic Medicine in Hamburg - Results of a 5-Year Period

Wulff, B.; Müller, K.; Heinemann, A.; Püschel, K. (Hamburg)
Band 39, Heft 6, Dezember 2012

Schwerpunkt: Aktuelle Trends beim Tissue Banking (in Zusammenarbeit mit der DGTI-Sektion "Gewebezubereitungen")

Koordination: Pruss, A.; Kalus, U. (Berlin)

Editorial

373 Aktuelle Trends beim Tissue Banking Pruss, A.; Kalus, U. (Berlin)

Originalarbeiten

376 Virus-NAT für HIV, HBV und HCV in postmortalen Blutproben, die bis $48 \mathrm{~h}$ nach dem Tod entnommen wurden - erste Ergebnisse Meyer, T.; Polywka, S.; Wulff, B.; Edler, C.; Schröder, A.S. (Hanburg); Wilkemeyer, I.; Kalus, U.; Pruß, A. (Berlin)

381 Validierung der Virus-NAT für HIV, HCV und HAV bei Verwendung von Post-mortem-Proben Gubbe, K (Plauen); Scharnagl, Y; Grosch, S; Tonn, T; Schmidt, M; Hourfar, M; Karl, A; Seifried, E (Frankfurt/M.); Wilkemeyer, I; Kalus, U (Berlin)

387 Validierung der mikrobiologischen Untersuchung von Gewebezubereitungen mittels BACTEC ${ }^{\text {TM }}$ Blutkulturflaschen

Schroeter, J.; Wilkemeyer, I.; Schiller, R.; Pruss, A. (Berlin)

391 Vergleich zwischen Bulbus- und Korneoskleralkomplex-Entnahme bei Hornhautspendern hinsichtlich der Rate mikrobieller Kontaminationen im Organkulturmedium - eine prospektive, monozentrische Studie über 9 Jahre

Schroeter, J; Wilkemeyer, I; Herrlinger, F; Pruss, A (Berlin)

395 CT-Läsionsmodell-basierte strukturelle Allografts: Maßgeschneiderte Herstellung und klinische Erfahrung

Brune, J.C.; Hesselbarth, U. (Berlin); Seifert, P.; Nowack, D (Hamburg); von Versen, R. (Wandlitz); Smith, M.D. (Berlin); Seifert, D. (Apolda)

405 Regionale Erfahrungen mit der postmortalen Gewebespende in einem rechtsmedizinischen Institut - Ergebnisse eines 5-Jahres-Zeitraums Wulff, B.; Müller, K.; Heinemann, A.; Püschel, K. (Hamburg)

\section{KARGER}

Fax +497614520714

Information@Karger.de www.karger.com 


\section{Vol. 39, Issue 6, December 2012}

409 Coding of Tissue Preparations with Eurocode in Germany

Knels, R. (Dresden); Moenig, H.J. (Berlin); Wittmann, G. (München); von Versen, R. (Wandlitz); Pruss, A. (Berlin)

\section{Abstracts}

417 45. Jahreskongress der Deutschen Gesellschaft für Transfusionsmedizin und Immunhämatologie (DGTI). 11.-14. September 2012, Graz

374 Imprint

375 Acknowledgement to Reviewers

394 Erratum

423 News / Ticker

424 Meetings and Conferences

425 Contents of Forthcoming Issues

426 Guidelines for Authors

427 Contents Vol. 39, 2012

\section{Band 39, Heft 6, Dezember 2012}

409 Kodierung von Gewebepräparationen in Deutschland

Knels, R. (Dresden); Moenig, H.J. (Berlin); Wittmann, G. (München); von Versen, R. (Wandlitz); Pruss, A. (Berlin)

\section{Abstracts}

417 45. Jahreskongress der Deutschen Gesellschaft für Transfusionsmedizin und Immunhämatologie (DGTI). 11.-14. September 2012, Graz

374 Impressum

375 Dank an die Gutachter

394 Erratum

423 News / Ticker

424 Tagungen und Kongresse

425 Themenvorschau

426 Hinweise für Autoren

430 Inhalt Band 39, 2012 